\title{
Linking Leadership Styles to Employee Performance in the Public Sector Organizations in Ghana: The Role of Organizational Commitment
}

\author{
Francis Donkor ${ }^{1}$ \\ ${ }^{1}$ Department of Accountancy and Accounting Information System, Kumasi Technical University, Ghana \\ Correspondence: Francis Donkor, Department of Accountancy and Accounting Information System, Kumasi \\ Technical University, Kumasi, Ghana. E-mail: lastygh@yahoo.com
}

Received: March 3, 2021

doi:10.5539/ijbm.v16n5p43
Accepted: March 26, 2021

Online Published: April 5, 2021

URL: https://doi.org/10.5539/ijbm.v16n5p43

\begin{abstract}
The study examines the link between leadership styles and employee performance in the public sector organizations with respect to organizational commitment. A total of 330 respondents were selected from ten public sector organizations in Ghana. A PLS-SEM analysis was conducted and was found that organizational commitment partially mediates the relationship between both transformational and transactional leadership styles and employee performance. The study concludes that organizational success largely depends on the commitment level of employees which helps reduce labor turnover. Theoretically, the study findings reveal that leadership is the main element of employee performance through the commitment of employees. Therefore, the effectiveness of these leadership styles in encouraging employee performance are dependent on organizational commitment.
\end{abstract}

Keywords: Transformational leadership, Transactional leadership, organizational commitment, Employee performance, Public sector organizations

\section{Introduction}

The phenomenon of leadership in the public sector organizations worth studying (Vogel \& Masal, 2015). This concept has created new challenges on public sector leaders to meet the growing pressures of work (van Wart, 2013). Despite the vast body of research in the literature regarding the phenomenon of leadership styles and its implications for organizational performance in large and multinational organizations (Boehma et al., 2015; Boies, Fiset \& Gill, 2015), leadership styles in the public sector organizations remains under-researched (Franco \& Matos, 2013). Research in public administration reveals that public sector leadership plays important role in organizational performance (Jensen et al, 2016; Caillier, 2016). Assuming a role in the public sector leadership is a bit of a difficulty in our part of the world where the perception of public enterprise not well cherished compared to that of privately owned. Given the positive relationship between leadership styles and organizational performance (Grobler \& Du Plessis, 2016; Almatrooshi, Singh, \& Farouk, 2016) it has become essential to understand leadership styles in public sector organizations fully.

Employee performance is said to be the value of the set of employee behaviors that contribute to the organizational goal (Ribeiro, Gomes \& Kurian 2018). Walumbwa \& Hartnell (2011) posit that the word performance is used to pass on the particular aptitude to be inspired, stirring, pioneering, and as a determinant to achieve organizational objectives. Among other things, leadership is a vehicle to stimulate employee performance and driving change in both private and public organizations (Bottomley et al, 2016; Ozsahin \& Sudak, 2015). This supports the idea that leadership in public sector is a key to employee performance (Jensen et al, 2016; van Wart, 2013). Yukl (2010) postulates that, leadership causes employee to achieve organizational goals. This is because organizational failures have partly been attributed to leadership styles, according to literature (Donkor, appienti \& Achiaah, 2021; Mohiuddin, 2017). They further argue that leadership is one of the factors that determine a successful organization.

Study findings have indicated that organizational commitment is among the variables that affect organizational activities and how employee performs (Ardiansyah \& Afandi, 2018; De Waal, Mroueh \& Schiavo, 2017; Latorre et al, 2016). While other studies have found positive relations between leadership and organizational commitment, and its effectiveness (Yusef, 2014), some other researchers have also revealed that organizational commitment as a mediator will improve employee performance (Dappa, Bhatti \& Aljarah, 2019). Therefore, the study sought to 
consider the link between these variables in the public sector organizations in Ghana.

The results of this research will provide useful information to the managers and leaders in the public sector organizations. They will understand leadership styles and how to relate them to an employee commitment of their organizations. Buckman (2004) suggests that increasing the level of effectiveness and performance of employees is an essential role of leaders. It is better to broaden managerial knowledge to understand what kind of leadership style that impacts employee performance. It will not be far from right to disseminate managerial knowledge of leadership and organizational commitment to employees within public organizations by doing so, current and future leaders would understand how to develop strategies that encourage employees in state enterprises to take up strategic positions to help achieve organizational objectives.

\section{Theoretical Framework and Hypotheses}

\subsection{Transformational Leadership and Employee Performance}

Transformational leadership (TFL) dates back decades before Burns (1978) discovery. He introduced leadership writings (Barroso, Villegas, \& Carlos, 2008). Transformational leaders can influence employees through inspiration and self-interest development that in turn, transforms them within the organization (Pieterse, Van Knippenberg, Schippers, \& Stam, 2010). This valuable addition to the employee ideas and interests by the leader motivates them to perform beyond expectation (Yukl, 2004). Kirschner, (2007) describes it as a task undertaken to make subordinates motivated by engaging in much higher ideas and moral values. According to (Pieterse et al., 2010; Salman et al., 2011), leaders with these traits need to inspire subordinates to act in the interest of the enterprise but not for themselves. Riggio (2006) also posits that TFL hovers around leaders' capacity to motivate and inspire employee to put the organizational interest above their interest. (Salman, Riaz, Saifullah \& Rashid, 2011; Pieterse et al., 2010), further state that leaders with TFL traits encourage subordinates to go after the status quo with a new perspective to achieve novelty in their job performance. They further assert that transformational leader strives on innovation as a pivot to stimulate employees to be inspired and allow individual development and growth (Pieterse et al., 2010). According to (Riggio, 2006) as cited by (Çetin, Karabay \& Mehmet, 2012; Saleem, 2015), there are four critical elements of transformational leadership style, namely; idealized influence, inspirational motivation, intellectual stimulation, and individualized consideration. Ruggieri (2009) explained that individuals are influenced via trust, respect, reposing confidence in them as followers by allowing them to take a stand on difficult issues, showing conviction, being focused on objectives of the entity, committed to their jobs, have strong values to work and ethically being responsible. A situation where the enterprise can offer economic and non-economic rewards to subordinates, the leader uses the reward to enhance the performance of the employees (Ahmad, Hussein \& Tariq, 2014). Mittal \& Dhar, (2015) suggest that transformational leads to subordinate performance. Existing literature on empirical research has revealed that transformational leadership behaviors have a significant influence on employee performance (Grant, 2012; Ispas, 2012). Wang, Tsui and Xin (2011) concluded in their research that transformational leadership predicts better contextual performance than others. Walumbwa \& Hartnell (2011) supported that transformational leadership influence subordinate performance.

\subsection{Transactional Leadership and Employee Performance}

Transactional leadership (TSL), is thought to be aligned with the public sector organizations where rewards and punishment is used to facilitate the achievement of organizational objective (Caillier, 2014). Unlike the TFL, TSL creates a mutual relationship with employees, where the contribution of both sides is acknowledged (Caillier, 2016). Dartey-Baah (2015) asserts that transactional leaders focus on results but not the needs and perceptions of the employees. This suggests that transactional leaders are practical oriented and strive to achieve set objectives and give rewards and punishment where it is due (Eliyana, 2010). Therefore, TSL becomes essential to approach when there is little room for an alternative method to execute plans, and the goals are clearly defined. Zagoršek, Dimovski \& Škerlavaj (2009) conclude that TSL results in employee compliance and a commitment to task objectives. The concern of Burns, (1978) was that the primary concern of leaders with TSL traits is not about how quality the work is but how to avoid resistance and make decisions effectively. This implies that transactional leaders do not show much concern about individual developmental needs but what can be offered to achieve set goals is their main concern (Northouse, 2015). To be effective, a transactional leader should recognize and monitor the accomplishment of employees and offer the necessary rewards to motivate them. Through this, monitoring mistakes and noncompliance could be identified, and correctional measures are applied. Pieterse et al., (2010) further state that transactional leader has the characteristics of remaining with the status quo to avoid risk. TSL is useful for improving leader effectiveness which engenders positive attitudes and performance among subordinates with contingent reward (Vito, Higgins, \& Denney, 2014). Again, most research findings also support the fact that 
transactional leadership style has a positive relationship with employee job performance (Raja \& Palanichamy, 2011). Caillier, (2014) contends that TSL has smaller effect of required significances.

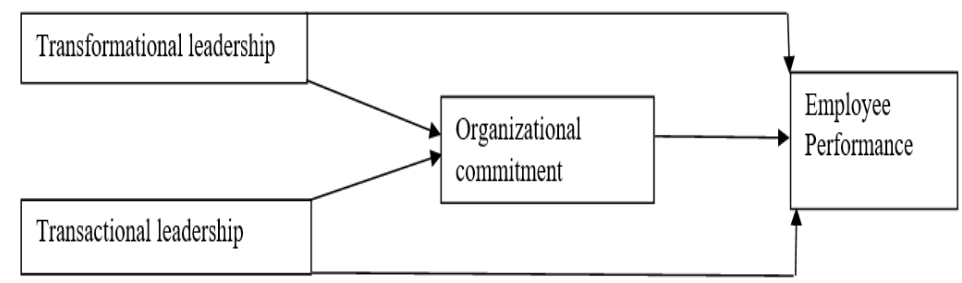

Figure 1. Hypothesized research model

\section{The Mediating Role of Organizational Commitment}

Organizational commitment (OC) has over the years been used as a mediating variable to examine the effects of transformational and transactional leadership on different employee behaviors including but not limited to performance (Retno, Setyaningrum \& Margono, 2017), job satisfaction and turnover intention (Barroso et al, 2008), motivation (Zareen \& Razzaq, 2013; Binfor et al., 2013). However, there is a dearth of studies on the analysis of the mediating effect of organizational commitment on the relationship among TFL and TSL and employee performance in Ghanaian public sector organizations. Again, extant literature suggests that effective leadership depends typically on individual circumstances. Given this, the study suggests that, direct effects of these leadership styles on employee performance may not give us a better understanding unless the study examines the effect of a mediating variable. $\mathrm{OC}$ is a valuable employee variable because a highly committed employee identifies with the objectives and values of the organization (Ramshida \& Manikandan, 2013). Barron \& Chou, (2016) suggest that employee commitment is the proper indicator of work performance and that leaders and supervisors should pay keen attention to their commitment through reciprocity tendencies. Choi, Oh \& Colbert, (2015) further explained $\mathrm{OC}$ as discernment and beliefs in which an employee accepts the values, objectives, and goals of the organization and amenable to work and continue to be recognized as part and parcel of the enterprise. Meyer \& Herscovitch, (2001) suggest that $\mathrm{OC}$ is a force that will secure a follower to a course of action, which is of importance to one or more targets. Given this, OC is attributed to critical work-related factors such as absenteeism, labor turnover, performance, and loyalty to the organization (Alkhatani, 2016; Yousef, 2000). Again, (Meyer \& Allen, 1991), suggest a three-component model, defined in terms of desire of the employee to remain in the organization and help achieve organizational goals, the need for an employee to remain in the organization and help achieve objectives for identified reasons and finally, obligation stay with the organization for a longer period. These three components are described psychologically as affective, normative and continuance commitment (Gelaidan \& Ahmad, 2013). Jaros, (2012), believes that employee may be experiencing some psychic cost like a guilty conscience that would be incurred for breaking this obligation and leaves the organization. Entity managers and leaders need specific measures that may increase organizational commitment within the entity (Al Ariss, Cascio \& Paauwe, 2014). Dey, (2012) suggests the confident practice of the employer procedural justice within the organization (Gumusluoglu, Karakitapoğlu-Aygüna \& Hirst, 2013). Moreover, job satisfaction will positively increase OC (Gallato et al, 2012).

\subsection{Effects of Organisational Commitment on Employee Performance}

There have been several pieces of literature that have looked into the OC constructs to determine their relationship with employee performance in organizations. For an organization to achieve its objective, employees must be much more committed to working towards that. Amoako-asiedu \& Obuobisa-darko (2017), suggest in their studies that there is a relationship between organizational commitment and employee performance. Many studies have used different procedures to determine that affective commitment has a positive relationship with job performance (Saha, 2016; Afshari et al, 2016). Other studies have also shown that the use of multidimensional methods have proven no relationship between continuance commitment and job performance (Meyer et al., 2002). Many other studies have also concluded that organizational commitment has a positive relationship with subordinate job performance (Amoako-asiedu \& Obuobisa-darko, 2017; Park \& Seo, 2016; Retno \& Margono, 2017).

\subsection{Leadership Styles, Organisational Commitment, and Employee Performance}

Many scholars have found in many types of research that the performance of employees in an organization is somehow affected by a mediator or mediators. In this study, the researchers want to find how $\mathrm{OC}$ as a mediating variable affects employee performance. In our search, we realized among other things that many findings have 
stated that organizational commitment affects organizational activities and how it performs (Qaisar, Rehman \& Suffyan, 2012; Lee \& Chen, 2013). Lee (2010) found both TFL and TSL to have a positive and significant relationship with commitment. Chi et al. (2012), found that leadership styles and $\mathrm{OC}$ have a positive and significant relationship with job performance. In South Africa, (Wiza \& Hanganipai, 2014) found among the academics, similar results between TFL and affective and continuance commitment as having significant positive relations but TSL had significant relations with normative commitment. In Kenya, the study concluded that there should be further studies to conclude the relationship between leadership styles and OC.

Concerning the public sector (Liou \& Nyhan, 1994) revealed that effective public sector leaders should pay attention to affective commitment in order to inspire the subordinates to work beyond expectation. Goulet \& Frank, (2002) studied among employees in public, non-profit, and for-profit sectors and revealed that public sector among the three groups was least committed to their various organizations. Again, Himmet, Unal \& Cuhadar (2008) agrees with the low commitment in the public sector employees. The study found, among other things, that where there is role conflict, and ambiguity in work responsibilities, the level of OC is minimal. In sharp contrast, Markovits et al., (2010) found that public sector employees have a higher affective commitment and intrinsic satisfaction than their counterparts in the private sector. However, normative commitment and intrinsic satisfaction proved otherwise, but in aggregating the variables, one can deduce much stronger public sector employee relationship with OC and job satisfaction than the private sector. For effective performance by the employees, leaders must lay down enough factors to attract employees to work to attain the set objectives (Farjad \& Varnous, 2013; Gumusluoglu et al., 2013). Yiing, Zaman \& Ahmad (2009) concluded that organizational commitment as a mediator would improve subordinate job performance. Therefore, leadership influences employee commitment. So, when leaders portray a flexible leadership style, it will increase organizational commitment (Yeh, 2014). In all the studies analyzed so far, none of them have scientifically or propounded any theory that examines the exact relationship between leadership styles and subordinate performance. Given the arguments and discussions adduced above, we hypothesize that:

$\mathbf{H}_{1}$ : There is a statistically positive and significant relationship between TFL and employee performance in public sector organizations.

$\mathbf{H}_{2}$ : There is no statistically positive and significant relationship between TSL and employee performance in public sector organizations.

$\mathbf{H}_{3}$ : OC has a statistically positive and significant relationship with employee performance.

$\mathbf{H}_{4}$ : OC mediates the relationship between TFL and employee performance in public sector organizations.

$\mathbf{H}_{5}:$ OC mediates the relationship between TSL and employee performance in public sector organizations.

\section{Methodology}

\subsection{Participants and Procedure}

The data for this research was gathered from full-time employees from different organizations whose jurisdiction fall the public sector employees of Ghana using paper questionnaires. This was done to get a more profound and proper understanding of the general relationship structure of the constructs. All the respondents were employees in various hierarchies in various departments of the organizations. The administrators of the questionnaires ensured anonymity and confidentiality of the employees as victimization is common in public sector organizations in that part of the world. The employees were assessed based on their employment - full-time employees in the stateowned enterprises in Kumasi Metropolis and Sunyani Municipality of Ghana. A total of 400 questionnaires were sent out to respondents, 30 was unable to be returned with another 40 unusable because it lacked specific information that was very relevant for analysis. The descriptive statistics indicated that out of 330 respondents, $58.50 \%$ (193 respondents) are males. Most of the respondents (43.00\%) are between the ages of 30- 39 years of age. Majority of these public sector employees have experienced between $6-10$ years. About $57 \%$ of these employees are a bachelor's degree holders and $15 \%$ are a master's degree certificate holders. Again, the majority of these respondents being $55.15 \%$ have been under a supervisor for up to 3 years. Comparing it with the working length of these employees, one can conclude that internal transfers are frequent.

\subsection{Research Tool and Measurement Procedure}

The research instrument used for collecting primary data were Multifactor Leadership Questionnaire (MLQ) by Bass and Avolio (2004) and Meyer and Allen's 2004 Three Components model Employee Commitment Survey Questionnaire (OCQ) which is seen to be most widely used data collection methods in evaluation research as well as personal performance questionnaire adopted from (Yousef, 2000). The Questionnaires used for the final data collection was close-ended questionnaires. Questionnaires help gather information on attitudes, opinions, 
behaviors, facts, and other information.

\subsubsection{Multifactor Leadership Questionnaire (MLQ-5X Short)}

The study used a Multifactor Leadership Questionnaire introduced by Bass and Avolio (1994) to evaluate leadership styles and subordinate performance as one of the components of the questionnaire. This revised MLQ has five-point Likert scale with forty-five items that evaluate leaders and subordinates job performance. The rater form of which the subordinates use to assess leaders was considered. MLQ has been extensively used to measure the leadership styles and performance of leadership. Transformational leadership has four (4) dimensions, which include Idealized Influence, Inspirational Motivation, Intellectual Stimulation, and Individualized Consideration. Transactional leadership also has three (3) critical elements, including Contingent Reward (CR), Management by Exception (Active)(MBEA) and Management by Exception (Passive)(MBEP).

\subsubsection{Organizational Commitment Questionnaire (OCQ)}

Organizational commitment was assessed by the use of questionnaires introduced by (Meyer \& Allen, 2004) known as the Three-Component Model (TCM). Employee Commitment Survey (revised version) has been extensively used to measure three forms of employee commitment of an organization. The survey included three well-validated scales, the Affective Commitment Scale (ACS), the Normative Commitment Scale (NCS) and the Continuance Commitment Scale (CCS). Each was scored separately to identify the commitment level of each employee.

\subsubsection{Personal Performance Questionnaire}

This questionnaire was adapted from (Yousef, 2000) and are in two dimensions, which included quality of performance and productivity measure. There are four items which are self-evaluating in nature by the employee on his or her performance and productivity as compared with that of colleagues doing the same task. The first two items were used to evaluate the performance quality and how productive a subordinate is on his/her job and the other two questions solicited and evaluated subordinates work quality and how productive they are is compared with colleague employees performing a similar function. The researchers used a 5-point rater scale to rank the items from $1=$ very low to 5 = very high. The items included; 'What is the quality of your work?' 'What is the productivity rate of your work?', 'Assess the work performance of your colleagues as compared to yourself?' 'Assess your work performance in comparison with your colleagues who are doing the same work'(Yousef, 2000).

\section{Results}

Partial Least Squares Structural Equation Modeling (PLS-SEM) was adopted to test the hypotheses of the study using SmartPLS 3.3 was used to conduct data analysis of the study. PLS-SEM was deployed to test the reliability and validity of the adopted variables and also analyze the relationship between the variables - TFL, TSL, OC and Performance. All the major parts of structural equation model (SEM), measurement model and structural model were evaluated (Hair et al., 2017). The measurement model was evaluated by the use of convergent validity and discriminant validity to determine constructs reliability and validity. To establish this, the study examined the factor loadings, average variance extracted (AVE) and composite reliability. The results indicate that the construct items showed loadings exceeding 0.6 with AVE ranging from 0.534 to 0.639 after items with lower loadings below 0.6 were deleted. The composite reliability also showed favorable outcomes, ranging from 0.714 to 0.855 , exceeding the recommended threshold of 0.7 (Hair et al, 2017). The results again reveal that, the discriminant validity was adequate because the square root of AVE was higher than the inter-correlational values between constructs. Both composite reliability and Cronbach's alpha are being reported for upper and lower bounds to determine the actual reliability of the internal consistency reliability. Therefore, validity and reliability of the study was established. 
Table 1. Measurement model results

\begin{tabular}{llllll}
\hline $\begin{array}{l}\text { Construct } \\
\text { Variables }\end{array}$ & $\begin{array}{l}\text { Construct } \\
\text { Items }\end{array}$ & $\begin{array}{l}\text { Outer } \\
\text { Loadings }\end{array}$ & $\begin{array}{l}\text { Cronbach' } \\
\text { s } \\
\text { Alpha }\end{array}$ & AVE & $\begin{array}{l}\text { Composite } \\
\text { Reliability }\end{array}$ \\
\hline \multirow{3}{*}{ TFL } & Trans 1 & 0.726 & & & \\
& Trans 2 & 0.792 & 0.710 & 0.534 & 0.714 \\
& Trans 3 & 0.701 & & & \\
& Trans 4 & 0.722 & & & \\
TSL & Transact1 & 0.758 & & & \\
& Transact 2 & 0.865 & 0.718 & 0.639 & 0.728 \\
& Transact 3 & 0.771 & & & \\
OC & Commit 1 & 0.728 & & & \\
& Commit 2 & 0.803 & 0.774 & 0.596 & 0.855 \\
& Commit 3 & 0.784 & & & \\
Performance & Commit 4 & 0.761 & & & \\
& Perf 1 & 0.774 & & & \\
& Perf 3 & 0.693 & 0.722 & 0.579 & 0.802 \\
\hline
\end{tabular}

A single-factor test by Herman was used to evaluate the existence of common source bias in the study model. The results indicate that there is no one factor being appeared in the factor analysis. Also, non-rotated factor does not explain more than $50 \%$ of the co-variance among the indicators. Therefore, common source bias is not present in the current study.

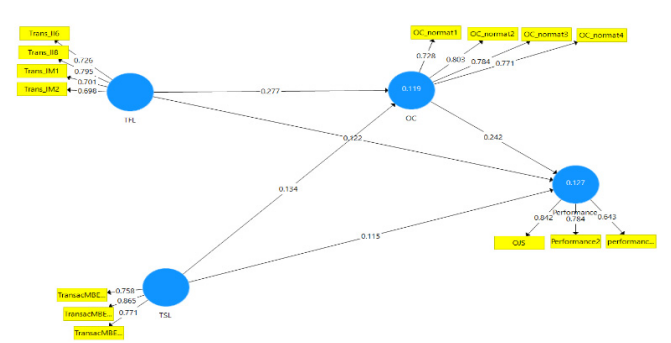

Figure 2. Path analysis

Table 2. Path analysis of direct effects

\begin{tabular}{llllll}
\hline Hypotheses & Beta & $\mathrm{t}$ - values & $\mathrm{p}$ - values & $97.5 \% \mathrm{CI}$ & Remarks \\
\hline $\mathrm{TFL} \rightarrow$ Performance & 0.188 & 1.969 & 0.049 & {$[0.004-0.243]$} & Accepted \\
$\mathrm{TSL} \rightarrow$ Performance & 0147 & 2.011 & 0.044 & {$[0.005-0.230]$} & Accepted \\
$\mathrm{OC} \rightarrow$ Performance & 0.242 & 3.721 & 0.000 & {$[0.07-0.361]$} & Accepted \\
\hline
\end{tabular}

Table 3A. Fornnel- Larcker Criterion

\begin{tabular}{lllll}
\hline & TFL & TSL & OC & Performance \\
\hline TFL & $\mathbf{0 . 7 3 1}$ & & & \\
TSL & 0.330 & $\mathbf{0 . 8 0 0}$ & $\mathbf{0 . 7 7 2}$ & \\
OC & 0.321 & 0.225 & 0.307 & $\mathbf{0 . 7 6 1}$ \\
Performance & 0.237 & 0.210 & & \\
\hline
\end{tabular}

Table 3B. Heterotrait - Monotrait criterion

\begin{tabular}{|c|c|c|c|c|}
\hline & TFL & TSL & $\mathrm{OC}$ & Performance \\
\hline \multicolumn{5}{|l|}{ TFL } \\
\hline TSL & 0.467 & & & \\
\hline $\mathrm{OC}$ & 0.477 & 0.302 & & \\
\hline
\end{tabular}




\begin{tabular}{llll}
\hline Performance & 0.355 & 0.300 & 0.410
\end{tabular}

The study further reported discriminant validity (DV) based on Fornell-Larcker criterion and Heterotrait-Monotrait criterion. The Fornell-Larcker criterion suggests that the square root of the AVE of each construct is higher than the construct's highest correlation with any other constructs in the model. This is depicted in those highlighted (diagonal values) and the correlation between the constructs in the off-diagonal position $(0.772,0.761,0.731$ and 0.800). Compared to Heterotrait-Monotrait (HTMT) ratio of correlation criterion, because it performs better than traditional approaches of discriminant validity assessment as the values are much lower than both Fornel-Larcker criterion and the cross-loadings using 0.702 as a suitable threshold level (Hair et al., 2017). This again is for the fact that even though these methods are used frequently in applied research, these methods do not allow reliably detecting discriminant validity issues.

Therefore, Discriminant Validity (DV) is better assessed using HTMT (Henseler, Ringle \& Sarstedt, 2015). DV is used to measure how different other constructs are using an empirical standard (Hair et al., 2017). To achieve a satisfactory level of DV, (Henseler et al., 2015) recommend HTMT value above 0.90. This means that the HTMT value above 0.90 depicts no DV, indicating that the constructs are conceptually similar. The outcome shows that all the constructs have HTMT score $<0.90$, and bootstrap confidence interval of $97.5 \%$ showed all corresponding values fallen below 1, thereby indicating that all constructs of the study (TFL, TSL, OC and Performance) are conceptually different and empirically distinct from each other.

\subsection{Assessment of Structural Modeling Path Coefficients}

The structural model was evaluated to test the conceptual model the hypothesized framework. Under this segment of the study, coefficient of determination $\left(\mathrm{R}^{2}\right)$, path coefficient (hypotheses tests), effect size $\left(\mathrm{f}^{2}\right)$ were evaluated (Hair et al., 2017). According to (Hair et al, 2014) $\mathrm{R}^{2}$ evaluates model's predictive power. $\mathrm{R}^{2} 0.75,0.50$, and 0.25 are regarded as 'substantial, moderate, and weak' (Hair et al., 2014). The results of the study suggest that the $\mathrm{R}^{2}$ is 0.127 for the performance endogenous latent variable. This means that the three latent variables (TFL, TLS, and $O C$ ) weakly explain $12.7 \%$ of the variance in employee performance. The inner model reveals that $T F L$ has the most potent effect on $O C(0.330)$ and TSL (0.290). Again, the hypothesized path relationship between $T F L$ and $O C$ is statistically significant. However, about the endogenous variable, Performance, $O C$ has the most potent effect on Performance (0.204) and then TFL (0.245) and TSL (0.064). Again, the hypothesized path relationship between $O C$ and Performance shows that statistically, it is significant, so do the hypothesized path relationship between TSL and Performance is not statistically significant. This is because its standardized coefficient $(0.051)$ is below the threshold of 0.1 . Thus, the study can conclude that TFL is moderately strong predictors of $O C$ and again, $O C$ is a weakly predictor of Performance, but $T L S$ does not predict both the mediator and the endogenous dependent variable.

Stone-Geisser's $Q^{2}$ value has been recommended by (Hair et al., 2014) for measuring the model's predictive relevance. The $\mathrm{Q}^{2}$ value is obtained using the blindfolding procedure with certain omission distance $(O D)$ such that, $\mathrm{Q}^{2}>0$ indicates that the model has predictive relevance for a specific endogenous construct. In calculating $\mathrm{Q}^{2}$ values in this research, $(O D)$ of 7 was considered to obtain the $\mathrm{Q}^{2}$ values of 0.064 and 0.060 for the endogenous variables $\mathrm{OC}$ and Performance.

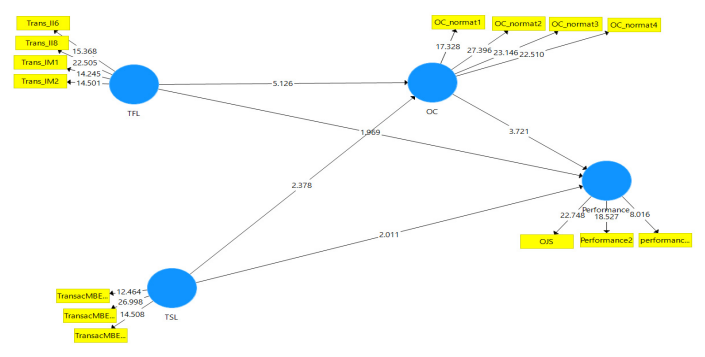

Table 4. Path analysis of indirect effects

\begin{tabular}{llllll}
\hline Hypotheses & Beta & $\mathrm{t}$ - values & $\mathrm{p}$ - values & $97.5 \%$ CI & Remarks \\
\hline $\mathrm{TFL} \rightarrow \mathrm{OC} \rightarrow$ Performance & 0.067 & 3.140 & 0.002 & {$[0.028-0.112]$} & Accepted \\
$\mathrm{TSL} \rightarrow \mathrm{OC} \rightarrow$ Performance & 0.032 & 2.150 & 0.032 & {$[0.006-0.008]$} & Accepted \\
\hline
\end{tabular}


The outcome in the table above reveals that our path coefficients are significant. The results indicate that all paths are statistically significant. The structural path of all the constructs is significantly based on a two-tailed test at $\mathrm{p}<0.05$.

In hypothesis 1 , the study predicted that TFL positively relates to employee performance. As shown in the table above, it was statistically significant at $(\beta=0.188, \mathrm{t}=1.969, \mathrm{p}<0.049)$. Again, hypothesis 2 also predicted that there is a statistically positive and significant relationship between TSL and employee performance. This was also proved decisive at $(\beta=0.147, \mathrm{t}=2.011, \mathrm{p}<0.044)$ which support the effects proposed in hypothesis 2 ; hence, it is validated.

Hypotheses 3 was also predicted that organizational commitment would statistically and significantly relates to employee performance. Table 4 above shows that $(\beta=0.242, \mathrm{t}=3.721, \mathrm{p}<0.000)$.

Hypotheses 4 and 5 were the mediating hypotheses. $\mathrm{H} 4$ predicted that $\mathrm{OC}$ will mediate the relationship between TFL and employee performance. The results in table 4 shows that OC partially mediates the relationship between TFL and employee performance $(\beta=0.067, \mathrm{t}=3.140, \mathrm{p}=0.002)$.

Hypothesis 5 was also predicted OC to have a statistically mediates the relationship between TSL and employee performance. The outcome falls within the threshold at $(\beta=0.032, \mathrm{t}=2.150, \mathrm{p}<0.032)$. This further suggests that organizational commitment partially mediates the two variables because both the direct and indirect effects are statistically significant. This implies that $\mathrm{OC}$ is not a fundamental variable in employee performance as far as public services is concerned. Therefore, leaders need to work on the style that attracts employees.

\section{Discussion}

The primary purpose of this study was to link leadership to employee performance in the public sector organizations in Ghana through organizational commitment which to the perception of the researcher have not been attended to for a very long time. Partly, the study is not consistent with the existing research showing that public sector organizations are not different in terms of leadership approach no matter where the business is located. Extant literature on leadership and employee performance has suggested that there is a positive relationship between transformational leadership, job performance and organizational commitment (Wiza \& Hanganipai, 2014; Saleem, 2015; Amoako-Asiedu \& Obuobisa-Darko, 2017). The findings of this study on transformational leadership have been consistent with all these research findings (Deluga \& Souza, 2011). The results further revealed that transformational leadership sets the center stage for managerial circumstances to foster the growth of public sector organizations. This is again supported by extant literature that found transformational leadership to foster subordinate opportunity to be creative (Afsar et al., 2016). Because of this, managers in public entities may be most effective if they display transformational leadership trait by fully adopting the constructs of a transformational leadership style. This may cause employees to be much more loyal and committed to their chosen job, and in turn, improve OC. This shows that TFL is an essential vehicle in fostering employee commitment, which implies that employee works harder to improve organizational effectiveness and hence, set objectives are achieved. Therefore, one can conclude that a TFL is a statistically positive predictor of organizational commitment and employee performance.

Again, various studies have revealed that TSL is a negative predictor of employee commitment and job performance (Afsari et al., 2016). The current study is not consistent with this study outcome where the relationship between TSL, OC and employee performance are negatively related. Some studies support this study. For instance, Alamir (2010) found that correlational and regression analysis revealed that TSL is positively related to OC. Lee (2010) Leaders who exhibit TSL traits should find innovative ways to motivate employees to go beyond their job responsibilities to improve organizational commitment and performance. In (Pieterse et al., 2010), they concluded in their study that transactional leadership is detrimental to subordinate innovative work behavior. The study reveals that TSL motivates through a process of exchange and that the rewards for employee to continue to perform over and above the required task must be encouraged. Even though TSL appeals to lower-order needs of the employees, it is presumed to have smaller impact on desirable consequences (Caillier, 2014). Leaders need to augment this with transformational attributes to develop other individual need to improve on their commitment levels.

OC has extensively discussed in the extant literature that supports the study findings. Studies in both public and private sector organizations are found to have a statistically positive and significant effect on employee job performance (Wu \& Chen, 2018). Yiing et al., (2009) further concluded that leadership styles influence organizational commitment, and in turn, the organizational commitment will affect employee performance and mediate the relationship between leadership style and employee performance. These findings suggest that employees in public sector, like any other sector, have the will to continue to work in the organization, and so the 
leadership have the responsibility to engender trust, motivation and inspire a sense of loyalty and duty. This will encourage subordinates to continue to give off their best for the achievement of objectives.

The study concludes that organizational success largely depends on how long the committed employee remains in the organization to reduce labor turnover and also understands the values and strategies of the enterprise. This creates strong ties and increases trustworthiness with clients and customers when they believe that employees at all times will be available to serve them.

Theoretically, the study findings reveal that leadership is the main element of employee performance through the commitment of employees. It contributes to our understanding and psychology of employee attitude towards performance and effects of the full range of leadership styles in organizational behavior. As TFL fosters innovativeness among employees, TSL also reward them with effective performance. Thus, the effectiveness of these leadership styles in encouraging employee performance is dependent on organizational commitment.

The findings of the study further imply that when employees perceive their leaders as adopting behavior that allows them to take part in decision making, they become more committed to the enterprise, more loyal to the course of the entity and improve on their job performance. This encourages a reciprocal gain sharing which leads to employee commitment and improved performance thereon as suggested by (Donkor \& Zhou, 2020). Again, in improving employee job performance and commitment, managers should adopt appropriate leadership behavior. Appropriate human development training programs should be developed to shape subordinate's leadership needs of the enterprises through the development of a succession plan that reduces the central government's interference. This will motivate subordinates to be more committed to the course of the state enterprises. After all, they may feel that the future is bright if they continue to improve on their performance. The study is no doubt has some implications for leaders who wish to stimulate and transform their entities to keep their valuable resources, human, for them to stay committed to reduce high labor turnover and also improve on productivity through working beyond responsibilities. It is essential for managers in public institutions to understand the leadership strategy necessary to inspire subordinates to go beyond their expectations to help achieve set goals. Subordinates who are committed to organizational objectives perform efficiently and effectively to achieve organizational objectives. Again, leaders should vary their leadership styles to suit the situation and further empower subordinates to take up higher responsibility through delegation and involvement in decision making especially on matters that bother on their organizational well-being and job security.

\section{Limitations and Future Research}

The study even though has provided enormous contributions to the leadership and organizational literature, there are certain limitations that need to be considered. The study was a cross-sectional design and for that matter failed to deal with the causality. The author suggests that future study could consider individual organizations and report individually. Therefore, the analysis and findings would be based on individual entities. Even though the study did not report any presence of common method bias, future studies should separate the collection of data involving dependent variables and independent variables to avoid self-reporting and perceptual measures from the same source.

\section{References}

Ahmad, N., Hussain, A., \& Tariq, M. S. (2014). Linkage Between Leadership Styles and Employee Performance. International Journal of Accounting Research, 2(1), 21-29.

Al Ariss, A., Cascio, W. F., \& Paauwe, J. (2014). Talent management: Current theories and future research directions. Journal of World Business, 49, 173-179. https://doi.org/10.1016/j.jwb.2013.11.001

Alamir, I. (2010). Testing the Impact of Transformational and Transactional Leadership on Job Satisfaction and Organizational Commitment in Private Syrian Organizations. International Journal of Arts and Sciences, $3(12), 405-415$.

Alkhatani, A. H. (2016). The Influence of Leadership Style on Organizational Commitment: The Moderating Effect of Emotional Intelligence. Business and Management Studies, 2(1), 23-34.

Amoako-asiedu, E., \& Obuobisa-darko, T. (2017). Leadership , Employee Engagement and Employee Performance in the Public Sector of Ghana. Journal of Business and Management Sciences, 5(2), 27-34. https://doi.org/10.12691/jbms-5-2-1

Angle H. L., \& L. M. B. (1994). Organizational commitment and employees' performance rating: Both type of commitment and type of performance count. Psychol. Report, 75, 1539-1551.

Barron, K., \& Chou, S. Y. (2016). Developing normative commitment as a consequence of receiving help: The 
moderated mediating roles of team-member exchange and individualism/collectivism-A multi-level model. Journal of Management Sciences, 3(2), 141-158.

Barroso, C. C., Villegas, P. M. M., \& Casillas, B. J. C. (2008). Transformational leadership and followers' attitudes: the mediating role of psychological empowerment, Management. The International Journal of Human Resource, 19(10), 1842-1863, https://doi.org/10.1080/09585190802324601

Benkhoff, B. (1997). Ignoring commitment is costly: New approaches establish the missing link between commitment and performance. Human Relations, 50(6), 701-726. http://dx.doi.org/10.1177/001872679705000604

Bilal, A., Yuosre, F., \& Badir, B. B. S. (2016). Transformational and transactional leadership and employee's entrepreneurial behavior in knowledge-intensive industries. The International Journal of Human Resource Management, 2-26. https://doi.org/10.1080/09585192.2016.1244893

Buckman, J. (2004). A time to direct, a time to support. Fire Chief, 18-19.

Burns, J. M. (1978). Leadership. New York: Harper and Row.

Çetin, M., Karabay, M. E., \& Mehmet, N. (2012). The Effects of Leadership Styles and the Communication Competency of Bank Managers on the Employee's Job Satisfaction: The Case of Turkish Banks. Journal of Procedia - Social and Behavioral Sciences, 58, 227-235.

Chi, H. K., Lan, C. H., \& Dorjgotov, B. (2012). The moderating effect of transformational leadership on knowledge management and organizational effectiveness. Social Behavior and Personality, 40(6), 1015-1024.

Choi, D., Oh, I. S., \& Colbert, A. E. (2015). Understanding organizational commitment: A meta-analytic examination of the roles of the fivefactor model of personality and culture. Journal of Applied Psychology, 100, 1542-1567. https://doi.org/10.1037/ap10000014

Deluga, R. J., \& Souza, J. (2011). The effects of transformational and transactional leadership styles on the influencing behaviour of subordinate police officers. Journal of Occupational Psychology, 64(1), 49-55. Retrieved from http://dx.doi.org/10.1111/j.2044-8325.1991.tb00540.x

Dey, T. (2012). Predictors of organizational commitment and union commitment: A conceptual study. IUP Journal of Organizational Behavior, 11, 62-75.

Farjad, R. H., \& Varnous, S. (2013). Study of relationship of quality of work life (QWL) and organizational commitment. Research in Business. Interdisciplinary Journal of Contemporary, 4, 449-456.

Frederick, B., Sampson, K. B., Edith, A., Abbey, S. A. O., \& Gyepi-Garbrah, F. K. M. S. (2013). The Effect of Leadership Styles and Motivation on Employee Performance in Public Institutions : Evidence from Ghana. International Journal of Current Research, 5(9), 2667-2670.

Gallato, C. G., Rashid, S., Suryasaputra, R., Warokka, A., Reamillo, K. G., \& bin, \& Abdullah, H. H. (2012). Fostering niches among SMEs in Malaysia through organizational commitment, leadership, organizational culture and job satisfaction. Journal of Innovation Management in Small \& Medium Enterprises, 3, 1-12. https://doi.org/10.5171/2012.511352

Gelaidan, M. H., \& Ahmad, H. (2013). The factors effecting employee commitment to change in public sector: Evidence from Yemen. International Business Research, 6, 75-87. https://doi.org/10.5539/ibr.v6n3p75

Goulet, L. R., \& Frank, M. L. (2002). Organizational commitment across three sectors: Public, non-profit, and forprofit. Public Personnel Management, 31(2), 201-210.

Grant, A. M. (2012). Leading with Meaning: Beneficiary Contact, Prosocial Impact, and the Performance Effects of Transformational Leadership. Academy of Management Journal, 55, 458-476.

Gumusluoglu, L., Karakitapoğlu-Aygüna, Z., \& Hirst, G. (2013). Transformational leadership and R\&D workers' multiple commitments: Do justice and span of control matter? Journal of Business Research, 66, 2269-2278. https://doi.org/i:10.1016/j.jbusres.2012.02.039

Hair, J. F., Hult, G. T. M., Ringle, C. M., \& Sarstedt, M. (2014). A Primer on Partial Least Squares Structural Equation Modeling (PLS-SEM). Los Angeles: USA: SAGE.

Hair, J. F., Hult, G. T. M., Ringle, C. M., \& Sarstedt, M. (2017). A primer on partial least squares structural equation modeling (PLS-SEM) (2nd ed.). Thousand Oaks, CA.: Sage.

Henseler, J., Ringle, C. M., \& Sarstedt, M. (2015). A new criterion for assessing discriminant validity in variancebased structural equation modeling. Journal of the Academy of Marketing Science, 43(1), 115-135. 
https://doi.org/10.1007/s11747-014-0403-8

Himmet, K., Unal, A., \& Cuhadar, T. M. (2008). The effect of role conflict and role ambiguity on job satisfaction and organization commitment: A study in the public and private sectors. Journal of American Academy of Business, Cambridge, 13(2), 176-181.

ISPAS, A. (2012). Conceptual approach of leadership and employees' individual performance relationship. Annals of the University of Oradea. Economic Science Series, 21, 1021-1026.

Jackson, T. A., Meyer, J. P., \& Wang, X. H. F. (2013). Leadership, commitment, and culture: a meta-analysis. Journal of Leadership \& Organizational Studies, 20(1), 84-106.

Jaros, S. J. (2012). Evaluating the "few alternatives" dimension of continuance commitment: A comment on Johnson, Chang, and Yang (2010). Journal of Leadership, Accountability \& Ethics, 9, 63-71.

Kirschner, H. R. B. (2007). Are You a Transformational Leader? Physician Executive, 33, 54-57.

Lee, C., \& Chen, C. (2013). Relationship between employee commitment and job attitude and its effect on service quality. American Journal of Industrial and Business Management, 3, 196-308.

Lee, H. W. (2010). Relationship between leadership style and organizational commitment. Operating Management Reviews, 6(1), 87-95.

Liou, K. T., \& Nyhan, R. C. (1994). Dimensions of organizational commitment in the public sector: An empirical assessment. Public Administration Quarterly, 18(1), 99-118.

Markovits, Y., Davis, A. J., Fay, D., \& van Dick, R. (2010). The link between job satisfaction and organizational commitment: Differences between public and private sector employees. International Public Management Journal, 13(2), 177-196.

Meyer, J. P., \& Allen, N. J. A. (1991). three-component conceptualization of organizational commitment. Human Resource Management Review, 1(1), 61-89.

Meyer, J. P., \& Allen, N. J. (2004). TCM Employee Commitment Survey Academic Users Guide 2004.

Meyer, J. P., \& Herscovitch, L. (2001). Commitment in the Workplace: Towards a General Model. Human Resource Management Review, 11(3), 299-326.

Meyer, J. P., Stanley, D. J., Herscovitch, L., \& Topolnytsky, L. (2002). Affective, continuance, and normative commitment to the organization: A meta-analysis of antecedents, correlates, and consequences. Journal of Vocational Behavior, 61(1), 20-52.

Mittal, S., \& Dhar, R. L. (2015). Transformational leadership and employee creativity: mediating role of creative self-efficacy and moderating role of knowledge sharing. Management Decision, 53(5), 894-910.

Northouse, P. G. (2007). Leadership Theory and Practice (4th ed.). Thousand Oaks, CA.: Sage Publications.

Pieterse, A. N., Van Knippenberg, D., Schippers, M., \& Stam, D. (2010). Transformational and transactional leadership and innovative behavior: The moderating role of psychological empowerment. Journal of Organizational Behavior, 31, 609-623.

Qaisar, M. U., \& Rehman, M. S. (2012). Exploring Effects of Organizational Commitment on Employee Performance: Implications for Human Resource Strategy. Interdisciplinary Journal of Contemporary Research In Business, 3(11), 248-255.

Raja, A. S., \& Palanichamy, P. (2011). Leadership Style and its Impact on Organizational Commitment. AsiaPacific Business Review, 7(3), 167-175.

Ramshida, A. P., \& Manikandan, K. (2013). Organizational Commitment as a Mediator of Counterproductive Work Behavior and Organizational Culture. International Journal of Social Science \& Interdisciplinary Research, 2(2), 59-69.

Retno, P. S., \& Margono, S. S. (2017). Mediation of Relationships between Servant Leadership and Employee. Journal of Applied Management, (36), 693-701.

Riggio., E., \& Bass, M. B. (2006). Transformational leadership (2nd ed.). Mahwah, NJ: Erlbaum.

Ruggieri, S. (2009). Leadership in vitual terms: A comparison of transformational and transactional leaders. Social Behavior \& Personality: An International Journal, 37, 1017-1021.

Saha, R. (2016). Factors influencing organisational commitment- Research and lesson. Management Research and Practice, 8(3), 36-48. 
Saleem, H. (2015). The Impact of Leadership Styles on Job Satisfaction and Mediating Role of Perceived Organizational Politics. Journal of Procedia - Social and Behavioral Sciences, 172, 563-569.

Salman, Z., Riaz, A., Saifullah, M., \& Rashid, M. (2011). Leadership styles and employee performance (A Case Study of Shakarganj Mills Limited Jhang Pakistan). Interdisciplinary Journal of Contemporary Research in Business.

Suliman, A. M., \& Iles, P. A. (2000). Between control and commitment: Management and change as the art of balancing. Leadership and OD Journal, 12, 3-7.

Vito, G., Higgins, G., \& Denney, A. (2014). Transactional and transformational leadership. Policing: An International Journal of Police Strategies \& Management, 37(4), 809-822.

Walumbwa, F. O., \& Hartnell, C. A. (2011). Understanding transformational leadership-employee performance links: The role of relational identification and self-efficacy. Journal of Occupational and Organizational Psychology, 84(1), 153-172. Retrieved from http://dx.doi.org/10.1348/096317910X485818

Wang, H., Tsui, A. S., \& Xin, K. R. (2011). CEO leadership behaviors, organizational performance, and employees' attitudes. The Leadership Quarterly, 22, 92-105.

Wiza, M., \& Hanganipai, N. (2014). The Impact of Leadership Styles of Employee Organizational Commitment in Higher Learning Insititutions. Mediterranean Journal of Social Sciences, 5(4), 135-143.

Yeh, Y. (2014). Exploring the impacts of employee advocacy on job satisfaction and organizational commitment: case of taiwanese airlines,. Journal of Air TransportManagement, 36, 94-100.

Yiing, L. H., Zaman, K., \& Ahmad, B. (2009). The moderating effects of organizational culture on the relationships between leadership behaviour and organizational commitment and between organizational commitment and job satisfaction and performance. Leadership \& Organization Development Journal, 30(1), 53-86.

Yousef, D. A. (2000). Organizational commitment: a mediator of the relationships of leadership behavior with job satisfaction and performance in a non-western country. Journal of Managerial Psychology, 15(1), 6-28.

Yukl, G. (2004). Tridimensional leadership theory: A road map for flexible, adaptive leaders. Oxford.: Blackwell.

Zagoršek, H., Dimovski, V., \& Škerlavaj, M. (2009). Transactional and transformational leadership impacts on organizational learning. Journal for East European Management Studies, 14, 144-165.

Zareen, M., \& Razzaq, K. (2013). Job Design and Employee Performance: the Moderating Role of Employee Psychological Perception. European Journal of Business and Management, 5(5), 46-56.

\section{Copyrights}

Copyright for this article is retained by the author(s), with first publication rights granted to the journal.

This is an open-access article distributed under the terms and conditions of the Creative Commons Attribution license (http://creativecommons.org/licenses/by/4.0/). 